Article

\title{
Experimental Measurement of Bulk Thermal Conductivity of Activated Carbon with Adsorbed Natural Gas for ANG Energy Storage Tank Design Application
}

\author{
Atila Ertas ${ }^{1, *(\mathbb{D})}$, Christopher T. R. Boyce ${ }^{2}$ and Utku Gulbulak ${ }^{1}$ (D) \\ 1 Department of Mechanical Engineering, Texas Tech University, Lubbock, TX 79409, USA; \\ Utku.Gulbulak@ttu.edu \\ 25475 Saint Mary Dr NW, Rochester, MN 55901-3129, USA; ctrboyce@yahoo.com \\ * Correspondence: aertas@coe.ttu.edu
}

Received: 30 December 2019; Accepted: 27 January 2020; Published: 5 February 2020

check for updates

\begin{abstract}
The development of adsorptive natural gas storage tanks for vehicles requires the synthesis of many technologies. The design for an effective Adsorbed Natural Gas (ANG) tank requires that the tank be filled isothermally within a five-minute charge time. The heat generated within the activated carbon is on the order of $150 \mathrm{MJ} / \mathrm{m}^{3}$ of storage volume. The tank can be effectively buffered using Phase Change Material (PCM) to absorb the heat. The effective design of these tanks requires knowledge of the thermal properties of activated carbon with adsorbed methane. This paper discusses experimental measurements of the thermal conductivity of activated carbon with adsorbed methane. It was found that within the tank the thermal conductivity remains almost constant within the temperature and pressure ranges that ANG tanks will operate.
\end{abstract}

Keywords: gas storage; activated carbon; thermal conductivity; adsorbed natural gas (ANG)

\section{Introduction}

High-pressure gas storage vessels are one of the fastest-growing markets for advanced materials such as composites. Changing and escalating emissions standards are driving a 10 percent annual growth in alternative fuel pressure vessel sales [1]. Composite-reinforced pressure vessels are used for Compressed Natural Gas (CNG) products, buses, and trucks dependent on CNG and hydrogen alternatives to gasoline and diesel. Since they work under high pressures, a failure of pressure vessel can be very dangerous, causing gas leaks, fires, and even explosions. To answer this problem and increase performances of high-pressure hydrogen storage tanks, a multi-layered pressure vessel design was proposed featuring the dynamic wall capable of absorbing hydrogen [2,3].

The use of natural gas as transportation fuel is limited mainly due to its low volumetric energy density. CNG vehicles use natural gas that has been stored in heavy walled steel or carbon-fiber/epoxy pressure tanks. Sometimes, CNG vehicles have reduced cargo space because of the design and placement of the tank. CNG vehicles use methane stored at 3000 pia (20.7 MPa) to achieve densities of $10 \mathrm{lb} / \mathrm{ft} 3\left(160 \mathrm{~kg} / \mathrm{m}^{3}\right)$. High-cost, limited CNG refueling stations and space constraint inside the vehicle for CNG pressure vessels make them not a feasible alternative to petroleum fuels [4].

Adsorbed Natural Gas (ANG) became competitive to the CNG method because of the high energy density capability achievements [5-7]. ANG storage tanks use activated carbon as an adsorbent and can achieve storage densities as high as $24 \mathrm{lb} / \mathrm{ft}^{3}\left(384 \mathrm{~kg} / \mathrm{m}^{3}\right)$ at $500 \mathrm{psia}$ [8]. The disadvantage of ANG storage comes from the heat generated during the adsorption process. When natural gas is adsorbed 
on the activated carbon, the gas changes to a semi-liquid phase on the surface of the carbon. The heat transfer through the activated carbon with adsorbed methane is the focus of this paper.

The heat of adsorption is equal to or greater than the heat of vaporization. During tank charging, the tank heats up and limits the amount of gas which can be adsorbed. The heat of adsorption is approximately $150 \mathrm{MJ} / \mathrm{m}^{3}$ of tank volume. A five-minute fast charge of a $0.3 \mathrm{~m}^{3}$ ANG tank would require a heat transfer rate of $150 \mathrm{kWh}$ to maintain isothermal conditions in the tank. A typical vehicle with 10 cubic feet $\left(0.3 \mathrm{~m}^{3}\right)$ of storage has a range of 60 miles $(100 \mathrm{~km})$. The bulk thermal properties of the activated carbon and methane gas under charging conditions need to be known so that optimal design of ANG tanks can be achieved.

Phase Change Materials (PCM) used to buffer the tank thermally have been investigated at the Institute of Gas Technology (IGT). They have developed and patented this method [9]. The design that IGT uses is based on a computer model which simulated the adsorption process. Their model does consider changes in thermal conductivity and specific heat of the activated carbon with adsorbed methane. The aim of this research is to discuss experimental measurements of the thermal conductivity of activated carbon with adsorbed methane.

\section{Activated Carbon}

The adsorption phenomenon has been intensely studied since World War I, when activated carbons were first used in gas masks. Activated carbon is produced from carbonaceous raw material by carbonization and activation. During carbonization, most non-carbon elements such as oxygen and hydrogen are eliminated by pyrolytic decomposition. The residual carbon atoms group themselves into sheets of condensed aromatic ring systems with a certain degree of planar structure [10]. Figure 1 [11] shows the activated carbon structure. The aromatic sheets are intertwined and give rise to interstices and pore areas. The slit shaped interstice railed micro-pores have a width of $0.5-2 \mathrm{~nm}$. The pore areas which are called macro-pores are $2-50 \mathrm{~nm}$ in width. After carbonization, the material is activated. The activation process enhances the pore structure by removing tarry residues blocking the pores. Adsorption occurs in the slit shaped spaces between the aromatic sheets.
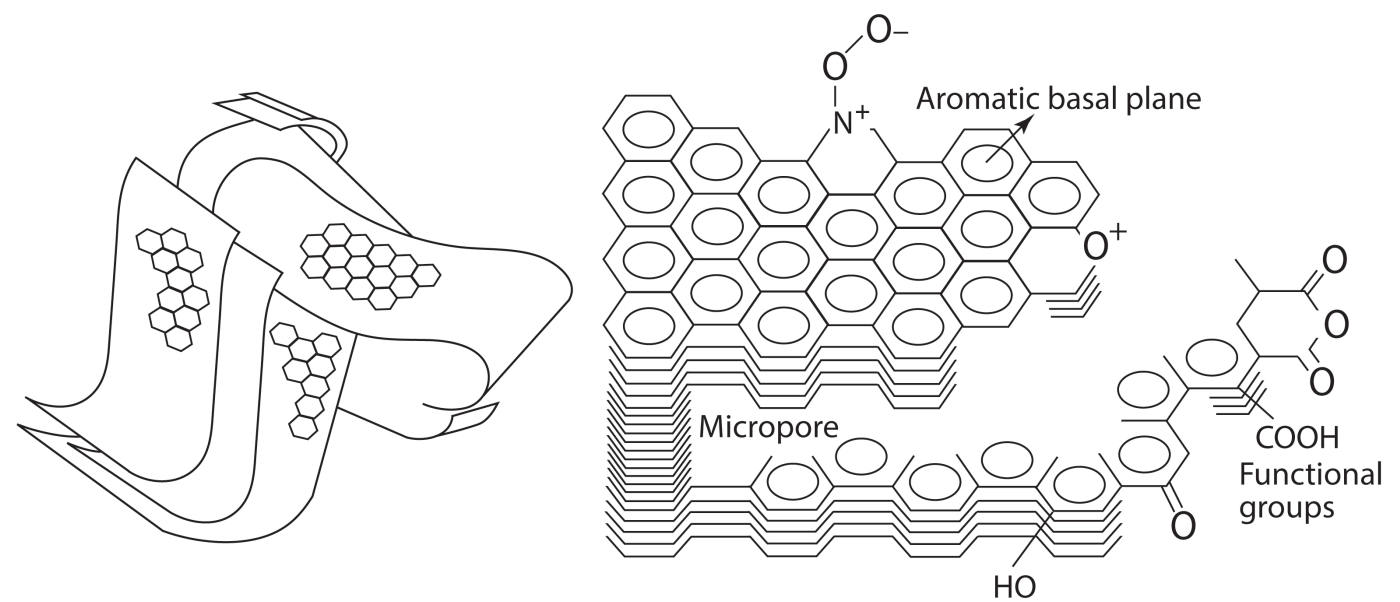

Figure 1. Structure of activated carbon materials (adapted from reference [11]).

Activated carbon provides an exceptional surface area, and a fine pure structure which adsorbs and traps gas particles. Environmental pollution concerns have led to the increase of the activated carbon demand, which is expected to continue rising in the near future. Activated carbon is used in a broad spectrum of applications, including methane and hydrogen storage, removal of water and air pollutants, food and beverage processing, solvent recovery, decaffeination, industrial pollution control, medicine, sewage treatment, teeth whitening, and biomedical applications, among various others. 
Carbon-based materials, such as activated carbons, have shown excellent potential for widespread applications. Activated carbons are carbonaceous adsorbents with an extremely crystalline form and high internal pore structure. A broad range of activated carbon products are available depending on the used raw material and activation method.

Many research studies have been reported in the literature about the adsorption of activated carbons for different applications.

To adsorb methane for storage, upgraded activated carbons using potassium hydroxide was investigated by Jung Eun Park et al. [12]. Improved Polyacrylonitrile-based activated carbon for carbon dioxide adsorption was investigated by Yu-Chun Chiang et al. [13]. They used potassium hydroxide $(\mathrm{KOH})$ to modify activated carbon which provided extra pore volume for adsorption. The adsorption of salicylic acid, acetaminophen, and methylparaben using activated carbons were investigated by Bernal et al. [14]. Their findings indicated that the pharmaceutical compounds have a low level of adsorption abilities in the activated carbon. Aloysius [15] used activated carbon samples at two pyrolysis temperatures and evaluated their adsorption capacity in aqueous solution. Research results showed that activated carbon adsorptive properties were influenced to a great extent by the pyrolysis temperature.

\section{Adsorption Theory}

A large variety of adsorbents, including activated carbon, have been investigated for adsorption studies. Karatza et al. [16] investigated the adsorption and desorption characteristics of the mercury vapor with silver nitrate impregnated commercially available activated carbon. It was shown that employed carbon was successful in capturing the mercury and obtained kinetic and thermodynamic parameters were crucial for designing a full-scale unit. Vorokhta et al. [17] compared the $\mathrm{CO}_{2}$ capture by three-dimensionally ordered micromesoporous carbon with carbon materials, carbon nanotubes, carbon nanohorns, and activated carbon. The capture performance of the proposed carbon was shown to be successful with high thermal stability and lower energy demand. Santonastaso et al. [18] investigated the use of permeable adsorptive barriers with activated carbon to mend the thallium contaminated aquifer. The finite element simulations showed that proposed barrier design can be considered as a successful tool. The proposed design was shown to be a better alternative to a continuous barrier. Hernandez-Monje et al. [19] presented a study in which the energy product from the interaction between three different organic solvents with three activated carbon samples with different physiochemical properties was measured. The highest interaction energy was found with benzene and toluene mixtures with activated carbon, thermally treated at $750{ }^{\circ} \mathrm{C}$.

The adsorption theory for microporous carbon is best predicted by the Dubinin and Radushkevich equation. This equation is known as the DR equation. The modern form of the DR equation is

$$
W=W_{o} \exp \left[-\left(\frac{A}{\beta E_{o}}\right)^{n}\right]
$$

where

$W_{o}$ is the total volume of micropores $\left(\mathrm{mg} \mathrm{g}^{-1}\right)$,

$\beta \quad$ is the affinity coefficient and $\beta$ for $\left(\mathrm{CH}_{4}\right)$ is equal to $0.5\left(\mathrm{~mol}^{2} \mathrm{kj}^{-2}\right)$ [20],

$E_{o}$ is the characteristic adsorption energy $(\mathrm{kj} / \mathrm{mol})$,

$n \quad$ is a homogeneity exponent which varies from 1.5 to 3 .

$A=R \times T \times \ln \left(p_{o} / p\right)$

$R \quad$ is the adsorbate gas constant $\left(8.314 \mathrm{j} \mathrm{mol}^{-1} \mathrm{~K}^{-1}\right)$,

$T$ is the temperature $\left({ }^{\circ} \mathrm{K}\right)$,

$p_{0} \quad$ is the gas critical pressure (atm). 
The DR equation is applicable for a wide range of gases and activated carbons [10]. The more well-known Langmiur equation is based on constant heat of adsorption regardless of coverage. It does not accurately predict the adsorption on highly captivated micro-porous carbons used in gas storage systems [21]. The adsorption of methane on ABG-40 and CALGON PCB carbons are shown in Figure 2a,b. The data used in these graphs came from experimental data compiled in reference [22].

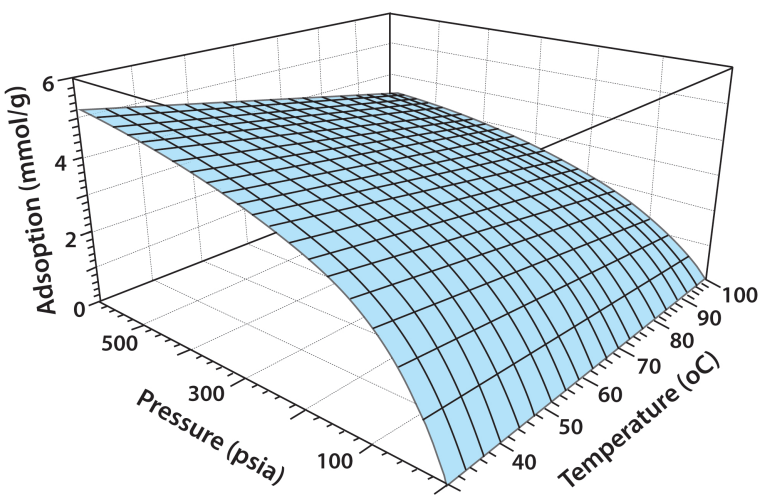

(a)

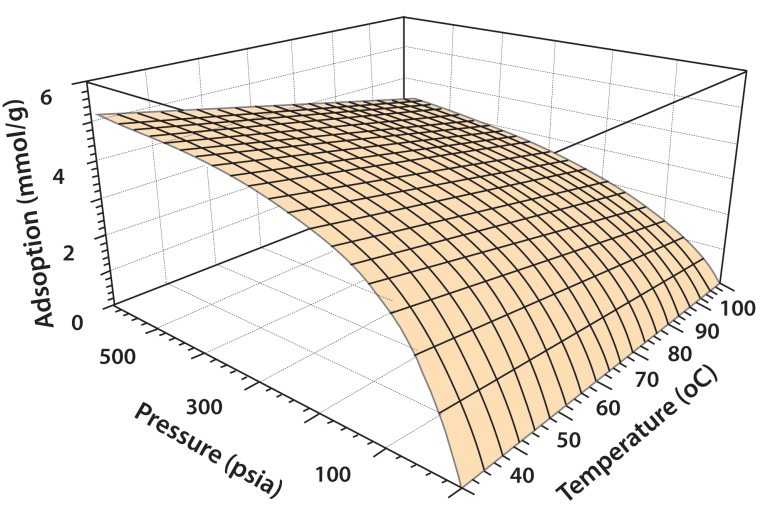

(b)

Figure 2. Methane adsorption on (a) ABG-40 activated carbon, (b) CALGON $12 \times 30$ activated carbon.

Typical values for characteristic heats of adsorption for activated carbon methane range from 17 to $18 \mathrm{~kJ} / \mathrm{mol}$ [23]. Micro-porous carbons tend to have higher characteristic heats of adsorption. The isosteric heat of adsorption for CALGON PCB $12 \times 30$ is $17.85 \mathrm{~kJ} / \mathrm{mol}$ [22]. The heat of adsorption limits the amount of gas adsorbed. During the fast charging of ANG storage tanks, this heat must be removed to enhance storage efficiency.

A 300-liter automotive storage tank requires 150 kilowatts of heat transfer during a five-minute isothermal charge. The temperature in the tank during charging will rapidly reach $100{ }^{\circ} \mathrm{C}[9]$. A parametric study was performed at Michigan State University on the effect of the heat of adsorption using a computer model. It was determined that the thermal conductivity and heat capacity of the activated carbon had the largest effect on storage efficiency [24]. The heat capacity of storage system can be increased by the use of PCM.

\section{Thermal Conductivity}

Numerous theoretical and experimental methods are reported in the literature to estimate materials' thermophysical properties. As far as the porous media such as activated carbon is concerned, studies about thermal conductivity have been a major research interest. There have been investigations for calculation of the thermal conductivity of packed beds. Kunii and Smith studied how to predict the effective thermal conductivity of beds of unconsolidated particles containing stagnant fluid [25]. Luikov et al. suggested a formulation to determine the effective thermal conductivity of powdered and solid porous materials in a wide-ranging temperature and various gas media [26]. Cheng et al. examined a method to estimate the effective thermal conductivity from the packing structure of a packed bed of mono-sized spheres in the existence of a stagnant fluid [27]. Composite adsorbents, containing activated carbon and expanded natural graphite, have been created, and their adsorption performance characteristics were tested by Wang et al. [28]. The thermal conductivity of small size cryopanel, which contains of a copper panel coated activated carbon adsorbent, was studied by Verma et al. [29].

The use of activated carbon has made it possible to store the same amount of gas contained in CNG tanks at a much lower pressure. Activated carbon alone is an excellent thermal insulator and, thus, a poor heat conductor. The thermal conductivity of activated carbon ranges from 0.05 to 0.10 Watts $/ \mathrm{m}^{\circ} \mathrm{K}[30]$. The thermal conductivity of methane gas is independent of pressure. Figure 3 
shows the thermal conductivity of methane measured at $101.35 \mathrm{kPa}$. The thermal conductivity of methane at $300{ }^{\circ} \mathrm{K}$ is 0.0344 Watts $/ \mathrm{m}^{\circ} \mathrm{K}$ [10]. The thermal conductivity of saturated liquid methane ranges from 0.089 to 0.189 Watts $/ \mathrm{m}^{\circ} \mathrm{K}[31]$.

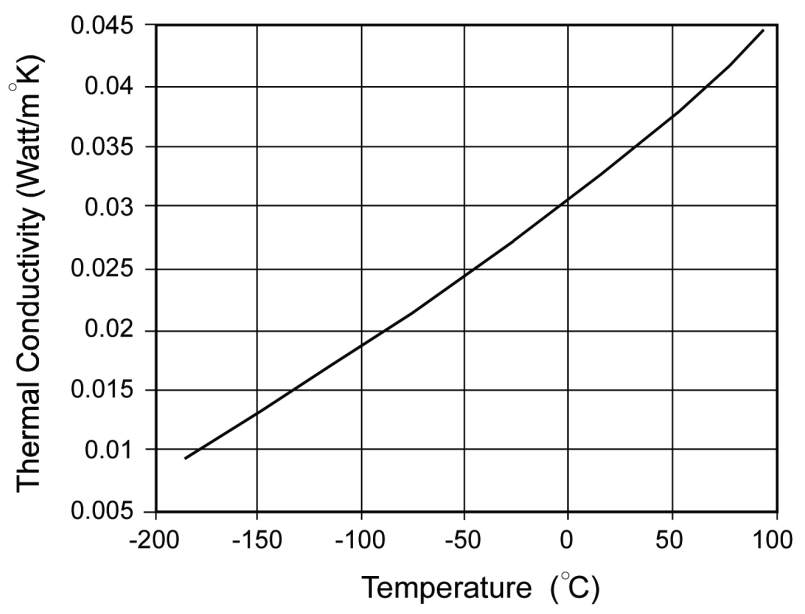

Figure 3. Thermal conductivity of methane.

The thermal conductivity of solids is directly related to the number of free electrons available. During adsorption, the activated carbons interstices become filled with methane gas at near liquid densities, thus decreasing the mean free path between electron shells. This phenomenon alone should increase the thermal conductivity of the activated carbon. The effect of a transport phenomenon caused by desorption and adsorption was disproved in the computer model of reference [32]. The energy required to liberate the methane molecules from the micro-pores is not present in the temperature gradients in an ANG storage tank during charge and discharge. The effect of contact resistance between carbon grain particles should also decrease since surface wetting of the activated carbon is also present. The net effect is an activated carbon with increased thermal conductivity.

\section{Thermal Conductivity Measurement Method}

The method used to measure the bulk thermal conductivity of the activated carbon with adsorbed methane was performed by determining the temperature distribution through the test tank from thermocouple probes and then curve-fitting the data. Fourier's Law was used to find the mean thermal conductivity for each test. The development of this method follows that of reference [33]. Starting with Fourier's Law for heat conduction,

$$
Q=-k \times A \times \nabla T,
$$

where

$Q \quad$ is the heat flow rate $\left(\mathrm{W} / \mathrm{m}^{2}\right)$,

$k$ is the thermal conductivity $\left(\mathrm{W} / \mathrm{m}^{\circ} \mathrm{K}\right)$,

$A$ is the area through which the heat flows $\left(\mathrm{m}^{2}\right)$,

$\nabla T$ is the temperature gradient $\left({ }^{\circ} \mathrm{K}\right)$.

In $1 \mathrm{D}$ cylindrical coordinates, the radial temperature gradient is

$$
\nabla T=\frac{\partial T}{\partial r}
$$

The heat conduction equation then becomes

$$
Q=-k \times A \times \frac{\partial T}{\partial r}
$$


Assuming the thermal conductivity is a function of temperature and substituting the area, $A$, with $2 \pi r L$ for heat transfer in the radial direction of a hollow cylinder, we have

$$
Q=-k(T) \times 2 \pi r L \times \frac{\partial T}{\partial r}
$$

where

$L \quad$ is the height of the cylinder (m),

$r \quad$ is the radius of the cylinder $(\mathrm{m})$.

Solving for $k(T)$ in Equation (5),

$$
k(T)=\frac{-Q}{2 \pi r L} \times \frac{\partial T}{\partial r}
$$

and by defining the mean thermal conductivity $K_{m}\left(T_{m}\right)$ and mean temperature as

$$
\begin{gathered}
K_{m}\left(T_{m}\right)=\frac{1}{\left(T_{2}-T_{1}\right)} \int_{T_{1}}^{T_{2}} k(t) d T \\
T_{m}=\frac{1}{\left(T_{2}-T_{1}\right)} \int_{T_{1}}^{T_{2}} T d T
\end{gathered}
$$

the mean thermal conductivity can be found by substituting Equation (6) into Equation (7)

$$
K_{m}\left(T_{m}\right)=\frac{1}{\left(T_{2}-T_{1}\right)} \int_{T_{1}}^{T_{2}} \frac{-Q}{2 \pi r L} \times \frac{\partial r}{\partial T} d T
$$

When the limits of integration in Equations (8) and (9) are changed to $r_{1}$ and $r_{2}, T_{m}$ and $K_{m}$ become

$$
\begin{gathered}
T_{m}=\frac{1}{\left(T_{2}-T_{1}\right)} \int_{r_{1}}^{r_{2}} \frac{\partial T}{\partial r} d r \\
K_{m}\left(T_{m}\right)=\frac{1}{\left(T_{2}-T_{1}\right)} \int_{r_{1}}^{r_{2}} \frac{-Q}{2 \pi r L} \times d r
\end{gathered}
$$

which then can be used to calculate $K_{m}\left(T_{m}\right)$, when $T(r)$ is known. It is evident that $K_{m}$ is only dependent on the two surface temperatures, for Equation (11) after simplification. In order to reduce the error associated with the thermocouple readings used in calculating $K_{m}$, a least squares curve-fit of the temperature distribution data was made [34]. The curve-fitting Equation (9) can then be used to calculate the thermal conductivity. $T(r)$ is found from the experimental measurements of temperature distribution through the carbon sample in the test tank. $T(r)$ is the least squares curve-fit to the function

$$
T(r)=A \ln ^{n}(r)+B
$$

where $A$ and $B$ are constants and $n$ is a nonlinearity exponent of the temperature distribution $(n=1$ for constant k) from the experimental data. Derivative of the function defined by Equation (12) is

$$
\frac{\partial T}{\partial r}=\frac{A \times n \times \ln ^{n}(r)}{r \times \ln (r)}
$$


$K_{m}(T)$ is calculated by substituting Equation (13) into Equation (9). $\frac{\partial T}{\partial r}$ is developed from the test data through logarithmic regression of the temperature and radius data. The heater power was developed by measuring the impedance of the resistive film and was verified to be constant within voltage range of 100-130 Volts AC. Since the power applied is AC, the RMS is the actual power developed by the heater.

\section{Experimental Test Setup}

The experimental test setup consisted of the following equipment: data acquisition and control computer, thermocouple signal conditioner, heater power control, gas measurement and control equipment, and an annular thermal conductivity test tank. Figure 4 shows the test setup used to measure the bulk thermal conductivity of the activated carbon with adsorbed methane (note: manual valves not shown in the schematic).

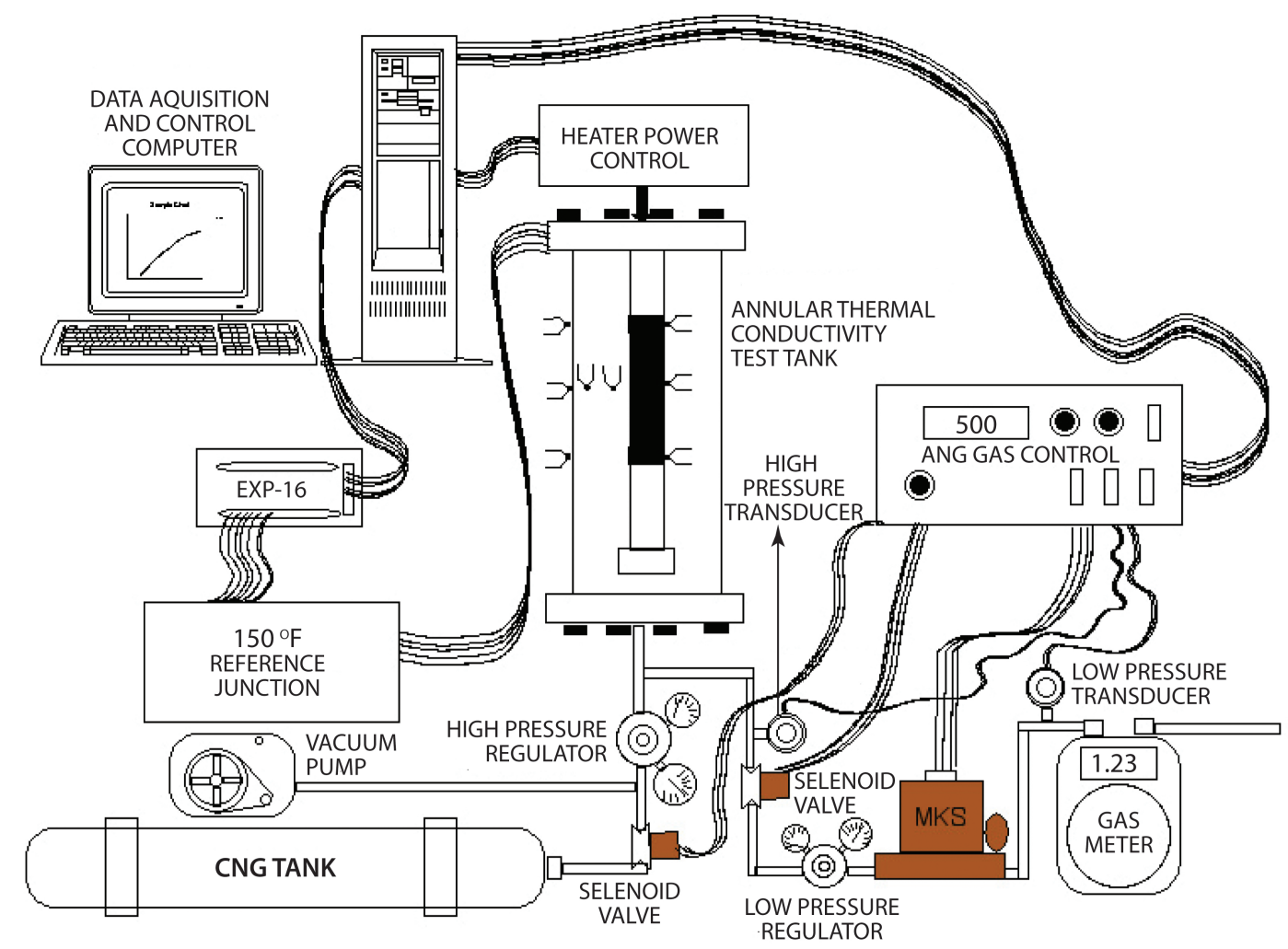

Figure 4. Experimental setup for testing bulk thermal conductivity of activated carbon with adsorbed methane.

\subsection{Heater Power Control}

The pulse burst method controls the power to the heaters by regulating the amount of time for which the power is switched "on" during a given cycle. The computer program was able to control the power to the heaters from 0 to $100 \%$ power in $1 \%$ increments with a power cycle of five seconds.

\subsection{Gas Measurement and Control}

The gas measurement and control equipment consisted of the DASH-16 board, refrigeration vacuum pump, pressure regulators, pressure transducers, solenoid valves, manual valves, CNG tank, bellows type gas meter, $1 / 2$ high pressure stainless steel tubing, ANG gas control box, and an MKS mass flow meter controller. The DASH-16 was interfaced to the ANG gas control box to control and monitor gas flow rate and pressures. The ANG Gas Control box was designed to operate in manual and computer-controlled modes. The charge and discharge solenoid valves controlled flow out of the 
CNG tank and test tank, respectively. The discharge flow rate was controlled and measured by an MKS 558A mass flow meter and an MKS 1559A mass flow controller calibrated for methane. The MKS unit uses an electromagnetic proportioning valve for flow control and a laminar heated tube sensor for mass flow determination. During discharge of the test tank, the amount of gas in the tank can be determined from the discharge flow rate integrated by the computer. A bellows type gas flow meter was modified with digital counter and used downstream of the MKS unit to measure the gas volume.

\subsection{Test Tank}

Testing the bulk thermal conductivity of the activated carbon with adsorbed methane was performed by constructing a test tank in which the radial heat flow could be controlled and temperature profile measured. The American Society for Testing and Materials (ASTM) method for measuring thermal conductivity of granular media used a guarded hot plate system; however, an annular design was necessitated by the pressure requirements of the methane on the activated carbon. The test tank shown in Figure 5 consisted of two circular plates, a heater pipe insert, and a tank body pipe section. The tank body section was seated in the o-ring grooves of the plates on the top of vinyl o-rings. Welded to the center of the top plate on the inside of the tank was the heater pipe insert. Kapton film heaters matching the inner circumference of the heater pipe insert were centered and attached with adhesive to the inside of the pipe.

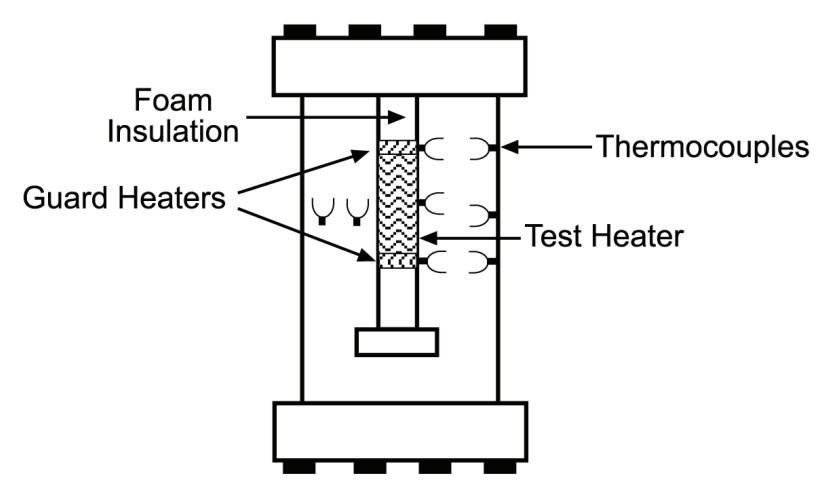

Figure 5. Annular Thermal conductivity test tank.

Two guard heaters were placed outside of the heater test area with power ratings of 28 watts per inch. After electrical connections were made, the heater pipe insert was filled with urethane foam insulation. Type $\mathrm{K}$ thermocouples were used to control the power to the heaters. Thermocouples were also located on the inside surface of the tank body section duplicating the vertical location of the heater thermocouples. These thermocouples were used to monitor axial heat flow across the test section. The radially strung thermocouples were used to measure the temperature profile of the activated carbon.

\subsection{Heater Pipe Insert}

The heater pipe insert was tested to verify the assumption of $1 \mathrm{D}$ heat transfer in the test section of the tank. A polyvinyl-chloride, PVC, pipe was used as the tank body. The heaters in the heater pipe insert were controlled by the computer system to maintain a $122^{\circ} \mathrm{F}\left(50^{\circ} \mathrm{C}\right)$ surface temperature. After steady state was reached, the radial temperatures were measured at $1 / 4$ inch $(6.35 \mathrm{~mm})$ increments for each vertical hole. The temperatures were recorded by inserting a 1/16 inch $(1.59 \mathrm{~mm})$ thermocouple probe into the holes and moving the probe inward $1 / 4$ inch $(6.35 \mathrm{~mm})$ after each measurement until the heater pipe insert was reached. The results show that the axial temperature variation in the test section area is isothermal, thus verifying the $1 \mathrm{D}$ assumption of radial heat transfer.

The computer code also performed data logging. All temperatures, pressures, and line voltage were monitored continuously and displayed. The calculations for the thermal conductivity were 
performed and also displayed. Additional subroutines were written for charging and discharging of the test tank.

\section{Test Procedure}

\subsection{Carbons Tested}

Two granular activated carbons were tested. The first carbon tested was Alamo brand ABG-40 activated carbon. The second carbon was CALGON PCB $12 \times 30$. Table 1 shows the data for these granular carbons provided by the manufacturers.

Table 1. Properties of activated carbons tested.

\begin{tabular}{lll}
\hline Properties $\downarrow$ & \multicolumn{1}{c}{ ABG-40 } & CALGON PCB \\
\hline Precursor & bitimus coal & Coconut shell \\
U.S Sieve Size & $8 \times 40$ & $12 \times 30$ \\
N2 BET Surface Area & $1000 \mathrm{~m}^{2} / \mathrm{g}$ & $1250 \mathrm{~m}^{2} / \mathrm{g}$ \\
Bulk Density & $0.52 \mathrm{~g} / \mathrm{cc}$ & $0.44 \mathrm{~g} / \mathrm{cc}$ \\
Particle Density & $1.3 \mathrm{~g} / \mathrm{cc}$ & $0.85 \mathrm{~g} / \mathrm{cc}$ \\
Pore volume & $0.85 \mathrm{cc} / \mathrm{g}$ & $0.72 \mathrm{cc} / \mathrm{g}$ \\
Specific heat & $580 \mathrm{~J} / \mathrm{kg}$ & $580 \mathrm{~J} / \mathrm{kg}$ \\
Cost & $\$ 2.00 \mathrm{per} \mathrm{kg}$ & $\$ 4.98 \mathrm{per} \mathrm{kg}$ \\
\hline
\end{tabular}

\subsection{Steady State Tests}

Each carbon was tested as follows. The activated carbon was poured into the test tank. The test tank was then agitated and refilled with more carbon. The refilling process was repeated until no further settling of the activated carbon occurred. The test tank was then sealed and the tank was evacuated using the refrigeration vacuum pump. The vacuum pump was operated for several days while the tank heaters maintained a $100{ }^{\circ} \mathrm{C}$ temperature to fully output gas from the activated carbon. After the out gassing process, the thermal conductivity of the activated carbon was measured. To measure the thermal conductivity, a fixed power setting was maintained to the heater test section. The guard heaters under PID control matched the test section heater's temperature. The steady state temperature profile was then recorded. The thermal conductivity was measured under a vacuum and with methane adsorbed. The methane was maintained at constant pressure using the computer control program. Tests were performed with methane at 20,100, 250, 350, and 500 psia. Power to the heater test section was varied from $1 \%$ to $10 \%$. Each test was run for $24 \mathrm{hrs}$ to ensure steady state conditions. When the test results were questionable, tests were repeated under the same conditions.

\section{Results and Discussion}

Vacuum tests of activated carbon sample's thermal conductivity were found to be about $0.033 \mathrm{Watt} / \mathrm{m}^{\circ} \mathrm{K}$. Typical values from literature range from 0.05 to $0.10 \mathrm{Watt} / \mathrm{m}^{\circ} \mathrm{K}$ [30]. The experimental values are slightly lower then values listed in literature. The lower values may be the result of the complete out-gassing of the activated carbon, which may not have been performed in the literature. Thermal contact resistance at the heater insert pipe and activated carbon interface could also cause the thermal conductivity measurements to be slightly lower. The thermal contact resistance is considered to be negligible and its effect is averaged with the least squares curve fit of the temperature distribution.

Tables 2-4 show the test results. Test results shown in Table 4 were performed with a modified test tank. The results of the bulk thermal conductivity of activated carbon with adsorbed methane were surprising. The bulk thermal conductivity increased dramatically with the addition of methane and remained almost constant for all the tests. The measured bulk thermal conductivity was found to be approximately $0.200 \mathrm{Watts} / \mathrm{m}^{\circ} \mathrm{K}$. 
The mean and the standard deviation of a set of data given in Tables 2-4 are given in Table 5, respectively. As seen from the table, calculated standard deviations are relatively small, which indicates that data values are clustered closely around the mean. In calculating standard deviation, data values corresponding to $\mathrm{P}=0$ psia are ignored.

Other researchers also studied thermal conductivity of activated carbon. Wang et al. [35] studied the adsorption performance of activated carbon-methanol systems. It was stated that while the thermal conductivity of granular activated carbon bed was $0.017 \mathrm{~W} / \mathrm{m}^{\circ} \mathrm{K}$, the thermal conductivity of solidified activated carbon bed was ranging from 0.27 to $0.34 \mathrm{~W} / \mathrm{m}^{\circ} \mathrm{K}$. Kuwagaki et al. [36] reported the estimated thermal conductivity value changes between 0.17 to $0.28 \mathrm{~W} / \mathrm{m}^{\circ} \mathrm{K}$. Py et al. [37] stated that the thermal conductivity value changes between 0.1 to $0.2 \mathrm{~W} / \mathrm{m}^{\circ} \mathrm{K}$ for unconsolidated activated carbon beds and consolidated beds.

Table 2. ABG-40 Bulk thermal conductivity measurements.

\begin{tabular}{ccc}
\hline $\mathbf{T}_{m}\left({ }^{\circ} \mathbf{C}\right)$ & $\mathbf{P}(\mathbf{p s i a})$ & $\mathbf{K}_{m}\left(\mathbf{W a t t} / \mathbf{m}^{\circ} \mathbf{K}\right)$ \\
\hline 40.82 & 0 & 0.03252 \\
40.86 & 0 & 0.03287 \\
54.45 & 0 & 0.03473 \\
54.45 & 0 & 0.03491 \\
34.35 & 20 & 0.19982 \\
34.46 & 20 & 0.20032 \\
55.43 & 20 & 0.21090 \\
55.54 & 20 & 0.21729 \\
31.68 & 100 & 0.19515 \\
35.13 & 100 & 0.19532 \\
36.24 & 100 & 0.19701 \\
41.14 & 100 & 0.20148 \\
57.18 & 100 & 0.21607 \\
57.38 & 100 & 0.22323 \\
58.58 & 250 & 0.22538 \\
58.60 & 250 & 0.22166 \\
58.60 & 250 & 0.22277 \\
41.45 & 275 & 0.20321 \\
38.63 & 350 & 0.20992 \\
38.65 & 350 & 0.20876 \\
42.65 & 350 & 0.21290 \\
\hline & &
\end{tabular}

Table 3. CALGON PCB $12 X 30$ bulk thermal conductivity measurements.

\begin{tabular}{ccc}
\hline $\mathbf{T}_{m}\left({ }^{\circ} \mathbf{C}\right)$ & $\mathbf{P}(\mathbf{p s i a})$ & $\mathbf{K}_{m}\left(\mathbf{W a t t} / \mathbf{m}^{\circ} \mathbf{K}\right)$ \\
\hline 64.33 & 0 & 0.03188 \\
64.33 & 0 & 0.03269 \\
33.3 & 20 & 0.18798 \\
55.46 & 20 & 0.21099 \\
34.09 & 100 & 0.19578 \\
56.62 & 100 & 0.21796 \\
33.92 & 250 & 0.19728 \\
55.04 & 250 & 0.21557 \\
\hline
\end{tabular}

The number of thermal couples were increased to and spaced $1 / 4$ inch $(0.635 \mathrm{~cm})$ apart. The tests were run based on the hypothesis that the bulk thermal conductivity would be proportional to the amount of methane adsorbed. Therefore, one would expect the data to follow the adsorption curves for methane. Based on this hypothesis, the thermal conductivity would increase rapidly between 0 and 100 psia and gradually increase to a maximum at 500 psia. This is evident from the data shown in Tables 2-4. As shown in Table 2, at high pressures, the trend for thermal conductivity has a slight increase with an increase in temperature. However, the presented results show that the bulk thermal 
conductivity measurements remained approximately constant for both temperature and pressure ranges. The bulk thermal conductivity measured was higher then what could be produced by just a combination of the activated carbon and gas phase methane.

Table 4. CALGON-2 PCB $12 X 30$ bulk thermal conductivity measurements.

\begin{tabular}{ccc}
\hline $\mathbf{T}_{m}\left({ }^{\circ} \mathbf{C}\right)$ & $\mathbf{P}(\mathbf{p s i a})$ & $\mathbf{K}_{m}\left(\mathbf{W a t t} / \mathbf{m}^{\circ} \mathbf{K}\right)$ \\
\hline 95.82 & 0 & 0.03343 \\
40.54 & 20 & 0.18693 \\
40.81 & 100 & 0.18627 \\
40.50 & 250 & 0.18971 \\
40.57 & 500 & 0.18683 \\
\hline
\end{tabular}

Table 5. Means and standard deviations of set of data given in Tables 2-4.

\begin{tabular}{lcc}
\hline Materials & Mean $(\boldsymbol{\mu})$ & Standard Deviation $(\boldsymbol{\sigma})$ \\
\hline ABG-40 & 0.20948 & 0.01039 \\
CALGON PCB 12X30 & 0.20426 & 0.00455 \\
CALGON-2 PCB 12X30 & 0.18744 & 0.00134 \\
\hline
\end{tabular}

Figure 6, 3D representation of bulk thermal conductivity, is generated using Tables 2-4. In this figure, since some of the data points are very close to each other, they are not all visible. Using Tables 2-4, results are also presented in Figures 7-9, respectively. With the exception of $P=0$ psia, Figure 7 clearly shows that, at all temperature and pressure ranges, bulk thermal conductivity of activated carbon is approximately $0.2 \mathrm{~W} / \mathrm{m}^{\circ} \mathrm{K}$. As shown in Figures 8 and 9, a similar argument can be made for CALGON PCB 12 X30 and CALGON-2 PCB 12X30.

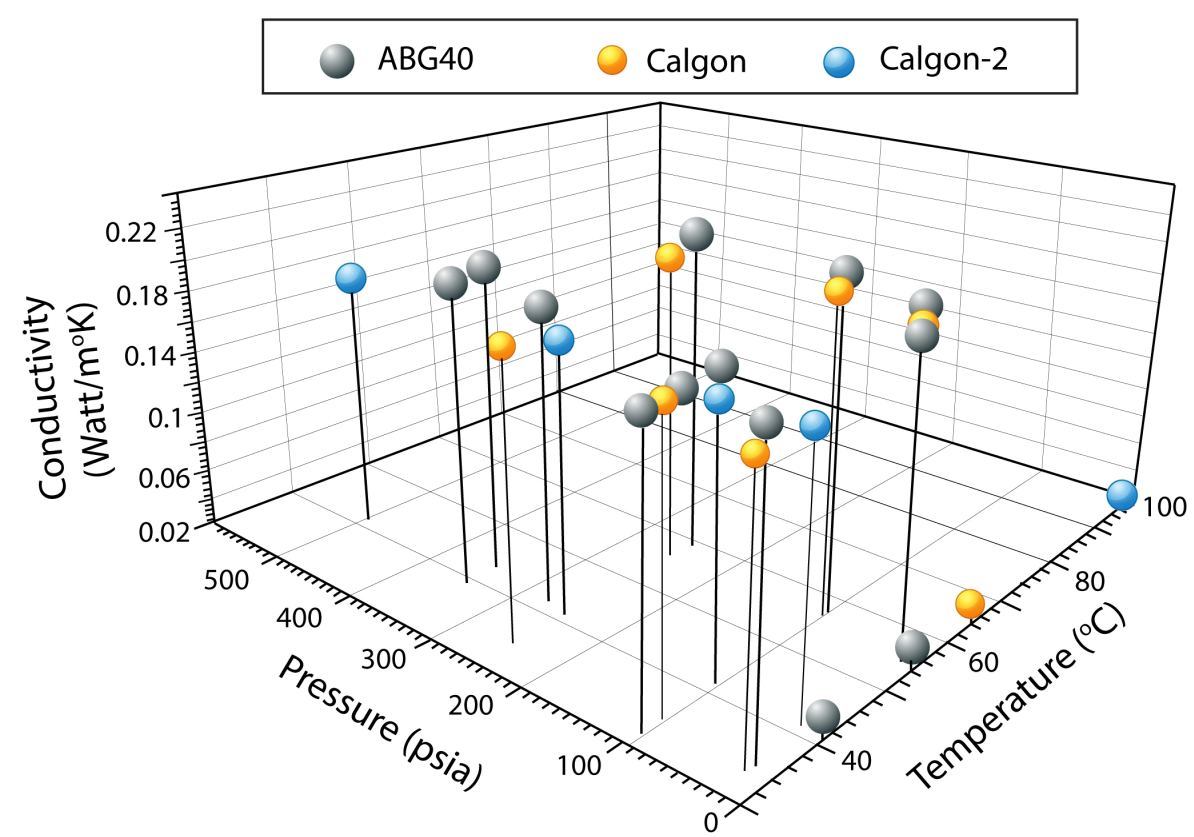

Figure 6. 3D representation of bulk thermal conductivity of ABG-40, CALGON PCB 12X30, and CALGON-2 PCB 12 X30.

The data were also analyzed on the assumption that free convection was dominating the heat transfer through the test tank. The correct measurement and characterization of the thermal conductivity of bulk materials such as activated carbon can pose a number of problems. For example, the loss of heat input power, resulting in the generation of heat for heating the activated carbon samples, can be very difficult to quantify [38]. The bulk thermal conductivity for the tests did not 
dramatically increase with increased power to the test section heater. The increased power to the test section should have resulted in increased free convection. Free convection does not appear to be a significant mechanism of the increased heat transfer. This free convection was not observed and was probably the result of the resistance to gas flow through the activated carbon being greater than the buoyancy effects on the gas. The transport phenomenon caused by desorption and adsorption from the hot side to the cold side also did not seem to be present. Phase change heat transfer rates are typical orders of magnitude larger and are also temperature sensitive. The increased in bulk thermal conductivity most likely is the result of methane adsorbed in the micro-pores of the activated carbon.

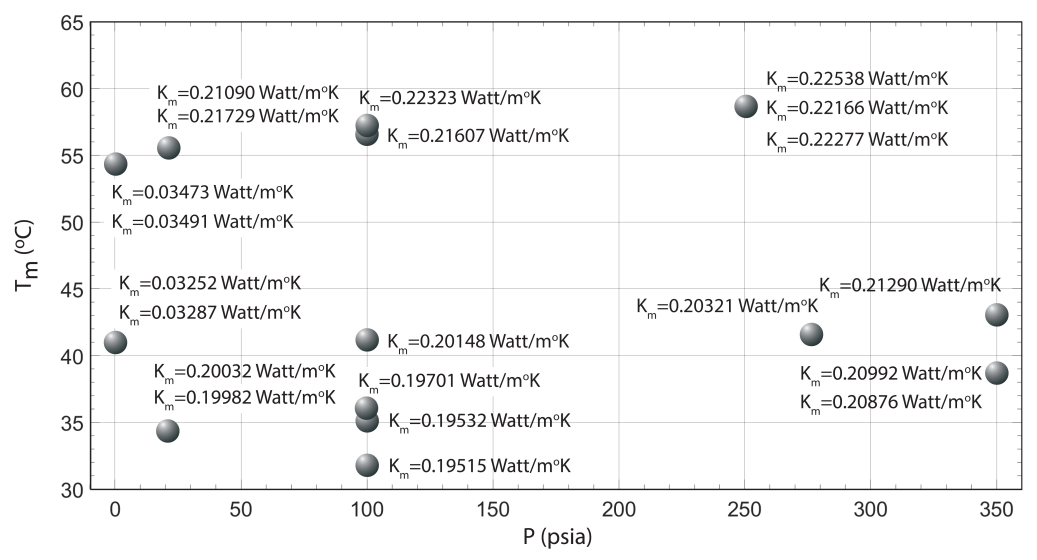

Figure 7. ABG-40 Bulk thermal conductivity measurements.

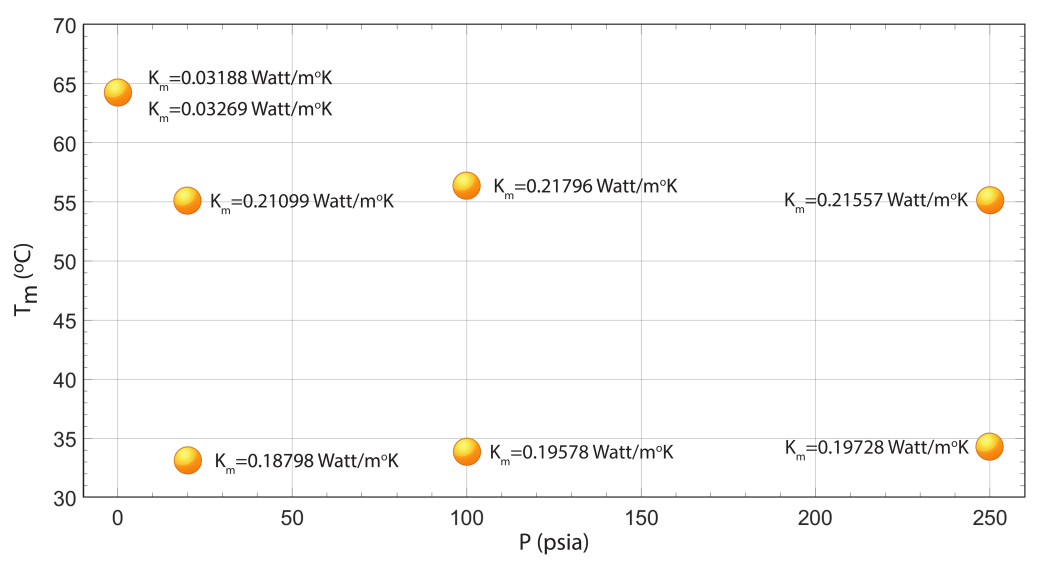

Figure 8. CALGON PCB $12 X 30$ bulk thermal conductivity measurements.

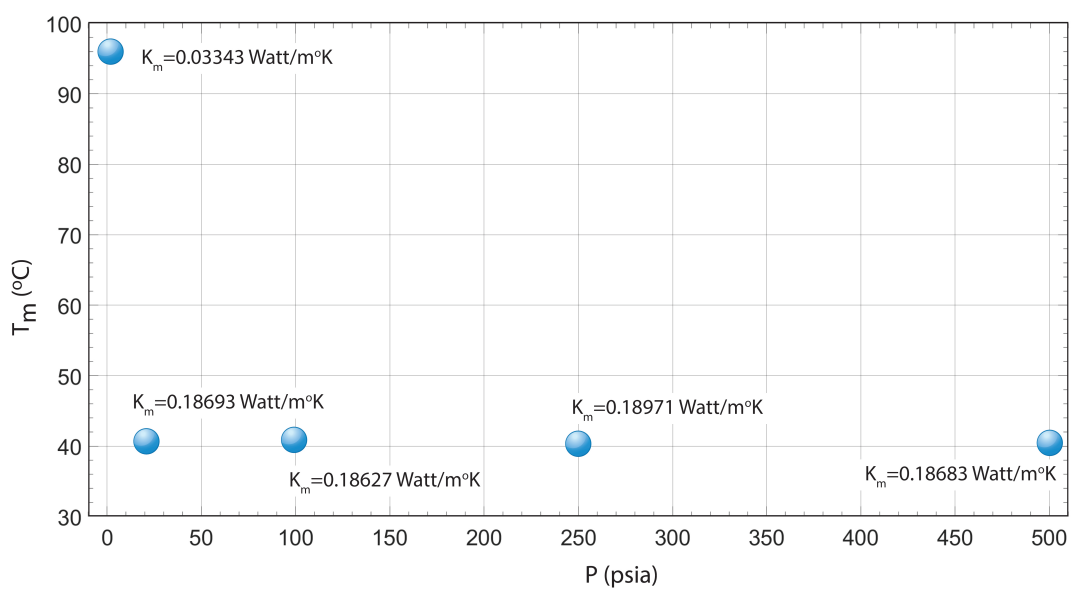

Figure 9. CALGON-2 PCB 12 X30 bulk thermal conductivity measurements. 
The test results through this research showed that, for ANG storage tank design, a bulk thermal conductivity of $0.200 \mathrm{Watt} / \mathrm{m}^{\circ} \mathrm{K}$ should be used. Heat transfer in the storage tank is much greater than what is predicted when using the thermal conductivity of activated carbon alone. Using the data from the parametric study at Michigan State, the storage efficiency of the ANG tank will increase $20 \%$. The effect on design of PCM buffered tanks will be even greater since the heat transfer rate is almost 2.5 times greater than the value used in the computer models at IGT.

\section{Conclusions}

This investigation to experimentally measure the bulk thermal conductivity of activated carbon was performed by developing a test setup which simulated ANG vehicle storage tanks. The test setup design was computer controlled and allowed for flexibility in the type of experiments that can be performed. The thermal conductivity of the activated carbon with adsorbed methane in the test tank was measured. It was found that the bulk thermal conductivity is six times larger than that for activated carbon alone and 2.5 times larger than the value used in computer simulations. The data from the thermal conductivity measurements resulted in the following conclusions:

- The bulk thermal conductivity will be fairly constant for ANG vehicle applications.

- The heat transfer in the tank is not dominated by free convection in the activated carbon bed.

- The bulk thermal conductivity appears to be the result of methane adsorbed in the micro-pores of the carbon at near liquid densities.

- Transport phenomena caused by adsorption and desorption do not appear to be a mechanism for heat transfer in ANG tank applications.

- The bulk thermal conductivity for CALGON PCB and ABG-40 was found to be approximately $0.200 \mathrm{Watt} / \mathrm{m}^{\circ} \mathrm{K}$ for the pressure range of 20 to $500 \mathrm{psia}$. Design of ANG storage systems may be improved using the information found by this research.

Author Contributions: This paper was produced from C.T.R.B.'s MS' thesis. A.E. was the advisor of C.T.R.B.' MS committee. AE write the paper. U.G. helped to develop art work and review the paper. All authors have read and agreed to the published version of the manuscript.

Funding: This research was funded by the Department of Mechanical Engineering at Texas Tech University.

Conflicts of Interest: The authors declare no conflict of interest.

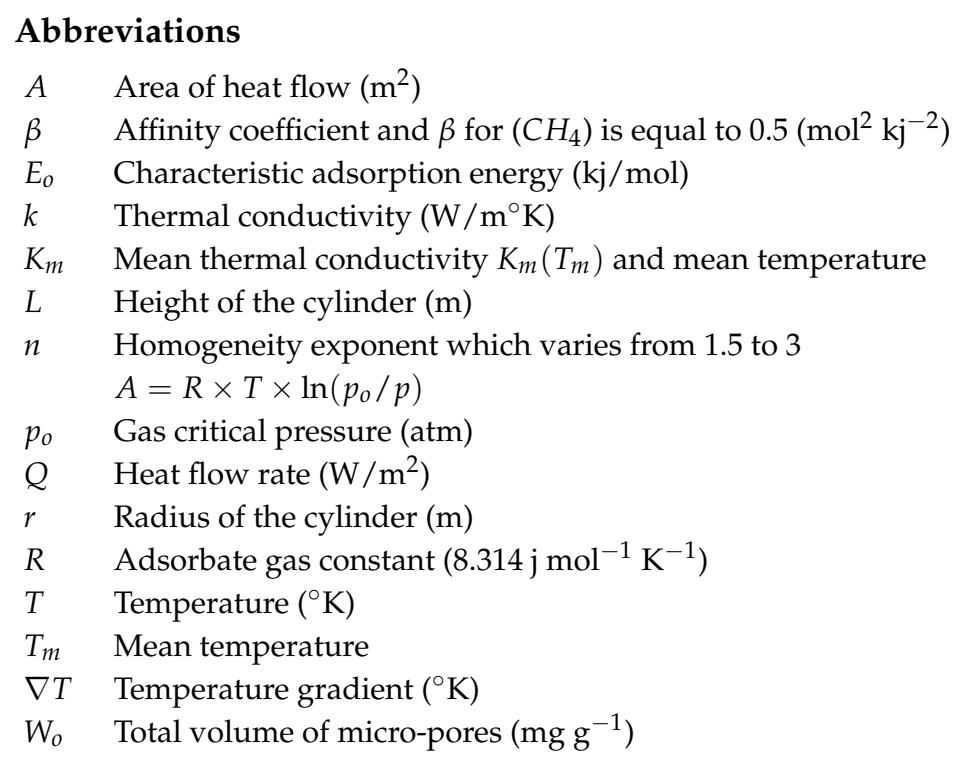




\section{References}

1. Pressure Vessels for Alternative Fuels, 2014-2023. CW Composite World. Available online: https: / / www.compositesworld.com/articles/pressure-vessels-for-alternative-fuels-2014-2023 (accessed on 13 November 2019).

2. Dubois, L.H. Adsorbed Natural Gas On-Board Storage for Light-Duty Vehicles. California Energy Commission, Energy Research and Development Division, Final Project Report. 2017. Available online: https:/ / ww2.energy.ca.gov/2017publications /CEC-500-2017-038/CEC-500-2017-038.pdf (accessed on 21 November 2019).

3. Cumalioglu, I.; Ertas, A.; Ma, Y.; Maxwell, T.T. High pressure hydrogen storage tank: A parametric design study. Trans. ASME J. Press. Vessel Technol. 2007, 129, 216-222. [CrossRef]

4. Cumalioglu, I.; Ertas, A.; Ma, Y.; Maxwell, T.T. State of the art: Hydrogen storage. Trans. ASME J. Fuel Cell Sci. Technol. 2008, 5, 34002-1-34002-10. [CrossRef]

5. Wegrzyn, J.; Wiesmann, H.; Lee, T. Low pressure storage of natural gas on activated carbon. In Proceedings of the SAE Post-Conference-Annual Automative Technology Development Contractors' Coordinating Meeting (ATD/CCM), Dearborn, MI, USA, 2-5 November 1992.

6. Vasiliev, L.L.; Larisa, K.; Mishkinis, D.; Rabetsky, M.I. Adsorbed natural gas storage and transportation vessels. Int. J. Therm. Sci. 2000, 39, 1047-1055. [CrossRef]

7. Akbarnrejad, M.M. Adsorbed natural gas technology development for transportation fuel. In Proceedings of the 19th World Petroleum Congress, Madrid, Spain, 29 June-3 July 2008; Document ID: WPC-19-2827.

8. BeVier, W.; Mullhaupt, J.; Notaro, F.; Lewis, I. Adsorbent-Enhanced Methane Storage for Alternate Fuel Powered Vehicles. SAE Technical Paper 891638. 1989. Available online: https:// doi.org/10.4271/891638 (accessed on 2 December 2019).

9. Jasionowski, W.J.; Kountz, K.J.; Blazek, C.F.; Tiller, A.J.; Gauthier, S.W.; Takagishi, S.K. A Thermal Energy Storage System for Adsorbent Low-Pressure Natural Gas Storage. In Proceedings of the International Conference and Exhibition on Natural Gas Vehicles-NGV-92, Gothenburg, Sweden, 23-25 September 1992.

10. Bansal, R.C.; Donnet, J.B.; Stoeckli, F. A Review of Active Carbon; Marcel Dekker: New York, NY, USA, 1988; p. 482.

11. Kurzweil, P. Electrochemical double-layer capacitors: Carbon materials. In Encyclopedia of Electrochemical Power Sources; Garche, J., Dyer, C., Moseley, P.T., Ogumi, Z., Rand, D.A.J., Scrosati, B., Eds.; Elsevier: Amsterdam, The Netherlands, 2009; Volume 1, pp. 634-648, ISBN 978-0-444-52093-7.

12. Park, J.E.; Lee, G.B.; Hwang, S.Y.; Kim, J.H.; Hong, B.U.; Kim, H.; Kim, S. The effects of methane storage capacity using upgraded activated carbon. Appl. Sci. 2018, 8, 1596. [CrossRef]

13. Chiang, Y.C.; Yeh, C.Y.; Weng, C.H. Carbon dioxide adsorption on porous and functionalized activated carbon fibers. Appl. Sci. 2019, 9, 1977. [CrossRef]

14. Bernal, V.; Giraldo, L.; Moreno-Pirajjän, J.C. Physicochemical properties of activated carbon:their effect on the adsorption of pharmaceutical compounds and adsorbate-Adsorbent. Interact. J. Carbon Res. 2018, 4, 62. [CrossRef]

15. Pam, A.A. Innovative activated carbon based on deep eutectic solvents (DES) and $\mathrm{H}_{3} \mathrm{PO}_{4}$. J. Carbon Res. 2019, 5, 43. [CrossRef]

16. Karatza, D.; Prisciandaro, M.; Lancia, A.; Musmarra, D. Silver impregnated carbon for adsorption and desorption of elemental mercury vapors. J. Environ. Sci. 2011, 23, 1578-1584. [CrossRef]

17. Vorokhta, M.; Morávková, J.; Řimnáčová, D.; Pilař, R.; Zhigunov, A.; Švábová, M.; Sazama, P. CO 2 capture using three-dimensionally ordered micromesoporous carbon. J. $\mathrm{CO}_{2}$ Util. 2019, 31, 124-134. [CrossRef]

18. Santonastaso, G.F.; Erto, A.; Bortone, I.; Chianese, S.; Di Nardo, A.; Musmarra, D. Experimental and simulation study of the restoration of a thallium (I)-contaminated aquifer by Permeable Adsorptive Barriers (PABs). Sci. Total Environ. 2018, 630, 62-71. [CrossRef]

19. Hernández-Monje, D.; Giraldo, L.; Moreno-Piraján, J.C. Immersion enthalpy of benzene/cyclohexane and toluene/cyclohexane binary mixtures into modified activated carbons. J. Therm. Anal. Calorim. 2019, 138, 2565-2575. [CrossRef]

20. Agarwal, R.K.; Schwarz, J.A. Analysis of high-pressure adsorption data activated carbon to obtain generalized characteristic and heats of adsorption curves. J. Colloid Interface Sci. 1988, 130, 137-145. [CrossRef] 
21. Gregg, S.L.; Sing, K.S.W. Adsorption Surface Area and Porosity, 2nd ed.; Academic Press Inc.: Cambridge, MA, USA, 1992.

22. Valenzuela, D.P. Adsorption Equilibrium Data Handbook; Prentice-Hall Inc: Upper Saddle River, NJ, USA, 1989.

23. Costa, E.; Calleja, G.; Marron, C.; Jimenez, A.; Pau, J. Equilibrium adsorption of methane, ethane, and propylene and their mixture on activated carbon. J. Chem. Eng. Data 1989, 34, 156-160. [CrossRef]

24. Talu, O. An overview of adsorption storage of natural gas. In Proceedings of the 4th International Conference on Fundamentals of adsorption, Kyoto, Japan, 17-22 May 1992.

25. Kunii, D.; Smith, J.M. Heat transfer characteristics of porous rocks. AIChE J. 1960, 6, 71-78. [CrossRef]

26. Luikov, A.V.; Shashkov, A.G.; Vasiliev, L.L.; Yu, E.F. Thermal conductivity of porous systems. Int. J. Heat Mass Transf. 1968, 11, 117-140. [CrossRef]

27. Cheng, G.J.; Yu, A.B.; Zulli, P. Evaluation of effective thermal conductivity from the structure of a packed bed. Chem. Eng. Sci. 1999, 54, 4199-4209. [CrossRef]

28. Wanga, L.W.; Tamainot-Teltob, Z.; Thorpeb, R.; Critophb, R.E.; Metcalfb, S.J.; Wanga, R.Z. Study of thermal conductivity, permeability, and adsorption performance of consolidated composite activated carbon adsorbent for refrigeration. Renew. Energy 2011, 36, 2062-2066. [CrossRef]

29. Verma, R.; Nagendra, H.N.; Kasthurirengan, S.; Shivaprakash, N.C.; Behera, U. Thermal conductivity studies on activated carbon based cryopanel. Mater. Sci. Eng. 2019, 502, 012197. [CrossRef]

30. Soffel, R.W. Activated Carbon, ETC 3rd ed.; Union Carbide Corp.: Houston, TX, USA, 1991; Volume 4.

31. ASHRAE HANDBOOK, Fundamentals SI Edition; American Society of Heating and Air-Conditioning Engineering Inc.: Atlanta, GA, USA, 1985.

32. Sangani, N. Effects of Heat of Adsorption on Methane Adsorption on Activated Carbon. Master's Thesis, Cleveland State University, Cleveland, OH, USA, 1991.

33. Ho, C.Y.; Taylor, R.E. High temperature thermal conductivity of soils. Thermal Conductivity. In Proceedings of the Eighth Conference; Plenum Press: New York, NY, USA, 1968.

34. Milton, J.S.; Arnold, J.C. Introduction to Probability and Statistics; McGraw Hills Inc.: New York, NY, USA, 1990.

35. Wang, L.W.; Wu, J.Y.; Wang, R.Z.; Xu, Y.X.; Wang, S.G.; Li, X.R. Study of the performance of activated carbon-methanol adsorption systems concerning heat and mass transfer. Appl. Therm. Eng. 2003, 23, 1605-1617. [CrossRef]

36. Kuwagaki, H.; Meguro, T.; Tatami, J.; Komeya, K.; Tamura, K. An improvement of thermal conduction of activated carbon by adding graphite. J. Mater. Sci. 2003, 38, 3279-3284. [CrossRef]

37. Py, X.; Daguerre, E.; Menard, D. Composites of expanded natural graphite and in situ prepared activated carbons. bCarbon 2002, 40, 1255-1265. [CrossRef]

38. Hlosta, J.; Zurovec, D.; Gelnar, D.; Zegzulka, J.; Necas, J. Thermal conductivity measurement of bulk solids. Chem. Eng. Technol. 2017, 40, 1876-1884. [CrossRef] 